\title{
Efeitos das escolhas, processos formativos e inserção profissional na construção de identidade(s) profissional(is) de formandos(as) em Controle Ambiental
}

\section{Effects of choices, formative processes and employability in the construction of professional identity(ies) of graduates in Environmental Control}

\author{
Alexandre Vanzuita ${ }^{1 *}$, Idorlene da Silva Hoepers, Deborah Duarte Pessoa de Faria, Rose \\ Fernandes de Souza, Renata Regina Teixeira
}

\begin{abstract}
RESUMO
O objetivo desta pesquisa foi analisar como as experiências no contexto de formação inicial e inserção profissional de formandos(as) em Controle Ambiental impactam a construção de identidade(s) profissional(is). A abordagem deste estudo é qualitativa, de característica analítico-descritiva e interpretativa, utilizando como técnica de produção de dados, o questionário semiestruturado e grupo focal, dirigido a onze (11) formandos(as). As experiências de formação inicial e inserção profissional constroem identidade(s) profissional(is) articuladas aos processos de pesquisa como princípio formativo e criação de métodos e metodologias que possibilitam transitar entre os conhecimentos teóricos e a prática da inserção profissional no contexto de se tornar técnico em Controle Ambiental.
\end{abstract}

Palavras-chave: Processos formativos; Inserção profissional; Identidade profissional.

\begin{abstract}
This research aims to analyze how experiences in the context of initial training and employability of graduates in Environmental Control impact the construction of professional identity(ies). The approach of this study is qualitative, with an analytical-descriptive and interpretive characteristic, using the semistructured questionnaire and focus group as a data production technique, aimed at eleven (11) trainees. The experiences of initial training and professional insertion build professional identity(ies) articulated to the research processes training principle and the creation of methods and methodologies that enable the transition between theoretical knowledge and the practice of employability in the context of becoming a technician in Environmental Control.
\end{abstract}

Keywords: Formative processes; Employability; Professional identity.

\section{INTRODUÇÃO}

No contexto de pesquisas sobre os processos formativos e de inserção profissional em cursos de licenciatura na educação superior, estudos desenvolvidos por Vanzuita

\footnotetext{
${ }^{1}$ Instituto Federal de Educação, Ciência e Tecnologia Catarinense - IFC.

*E-mail: alexandre.vanzuita@ifc.edu.br; idorlene.hoepers@ifc.edu.br.
} 
(2018a; 2018b), Vanzuita, Raitz e Garanhani (2020), Vanzuita e Garanhani (2021), Vanzuita (2021), entre outros, têm sido foco de investigações no sentido de analisar como essas dimensões impactam a construção de identidade(s) profissional(is). Os resultados de tais estudos possibilitam afirmar que a construção de identidade(s) profissional(is) de formandos(as) em cursos superiores passa por processos que exigem observar, dentro de cada contexto formativo, as implicações dos conhecimentos gerais e específicos na formação inicial e inserção profissional, os impactos das relações entre professores e estudantes no contexto formativo, as experiências de estágio e indução no trabalho e as contribuições da pesquisa e criação de métodos e metodologias nas aprendizagens desses formandos(as).

A partir dessa perspectiva e ampliando a discussão para outros níveis de ensino, nos debruçamos sobre o contexto formativo dos(as) formandos(as) do curso técnico em Controle Ambiental do Instituto Federal de Educação, Ciência e Tecnologia Catarinense - IFC Campus Camboriú a partir da elaboração da questão-problema: como as experiências no contexto de formação inicial e inserção profissional de formandos(as) do curso técnico integrado ao ensino médio de Controle Ambiental do IFC Campus Camboriú impactam a construção de identidade(s) profissional(is)?

A construção de identidade(s) profissional(is) tem como fundamento a concepção de Vanzuita (2018b, p. 155), quando aborda que essa construção “[...] deve contribuir para que os jovens sejam capazes de construírem conhecimento com autoria, autonomia e criatividade [...]". Nesse sentido, outras dimensões também podem ser consideradas nessa construção,

[...] como possibilidades de experimentar e sentir empatia, construir valores e atitudes profissionais fora do contexto da racionalidade técnico-científica, solucionar problemas, construir projeto pedagógico próprio, em que as experiências de formação inicial e inserção profissional podem contribuir e qualificar (VANZUITA, 2021, p. 62$63)$.

É importante destacar que a presente pesquisa torna-se relevante, uma vez que nas experiências de formação inicial e inserção profissional, nas pesquisas anunciadas no início deste trabalho, os processos de pesquisa como princípio educativo e formativo ${ }^{2}$ e a

\footnotetext{
${ }^{2}$ A pesquisa como princípio científico e formativo está fundamentada em Demo (2005). Significa provocar no processo de formação inicial e inserção profissional a "[...] elaboração própria, que inclui contraleitura assídua, coleta e tratamento de dados pertinentes, apresentação de trabalhos próprios constantemente, para garantir uma evolução sustentada e cada vez mais expressiva da competência” (DEMO, 2005, p. 95).
} 
criação de métodos e metodologias ${ }^{3}$ para aprender bem ${ }^{4}$ não são desenvolvidas integralmente nos processos de construção de identidade(s) profissional(is). Com efeito, o objetivo geral da pesquisa foi analisar como as experiências no contexto de formação inicial e inserção profissional de formandos(as) do curso técnico integrado ao ensino médio de Controle Ambiental do IFC Campus Camboriú impactam a construção de identidade(s) profissional(is). Como desdobramentos, os objetivos específicos elencados foram: a) Descrever o contexto de formação inicial do curso técnico integrado ao ensino médio de Controle Ambiental dos(as) formandos(as) do IFC Campus Camboriú; b) Caracterizar as experiências dos(as) formandos(as) em Controle Ambiental no seu contexto de formação inicial e inserção profissional e; c) Identificar se existe a articulação dos processos de pesquisa e criação de métodos e metodologias na construção de identidade(s) profissional(is).

Este texto está dividido em cinco (5) seções, considerando esta introdução como a primeira. A segunda seção aborda a caracterização do contexto formativo em Controle Ambiental a partir do Projeto Pedagógico de Curso de Educação Profissional Técnica de Nível Médio dialogando com autores da área da educação. A terceira seção dispõe sobre o caminho metodológico desenvolvido na investigação. Na quarta seção são discutidos os dados da pesquisa produzidos por meio do questionário semiestruturado e grupo focal. $\mathrm{Na}$ última seção, nas considerações finais, são tratadas as formas pelas quais as experiências de formação inicial e inserção profissional impactam na construção de identidade(s) profissional(is).

\section{A PERSPECTIVA FORMATIVA EM CONTROLE AMBIENTAL: UMA ANÁLISE DO PPCTM DO CURSO}

A contextualização por meio do Projeto Pedagógico de Curso de Educação Profissional Técnica de Nível Médio (PPCTM) (IFC, 2019a), do Curso Técnico de Controle Ambiental integrado ao ensino médio do IFC Campus Camboriú é relevante no âmbito da presente pesquisa, em razão de situar o leitor a respeito dos aspectos

\footnotetext{
${ }^{3}$ A criação de métodos e metodologias é baseada na perspectiva de saber combinar processos ou técnicas tão bem ou melhor quanto seus inventores (POUND, 2002).

${ }^{4}$ Aprender bem é conceituado por meio da perspectiva de Demo (2011), em que pressupõe a pesquisa e elaboração própria. Está escudada também pela concepção de estudar, pesquisar, elaborar com aprofundamento crítico e reflexivo, mirando sempre trajetória própria e autoral. Significa praticar o que Demo (2005) chama de "questionamento reconstrutivo" como propedêutica da ação do professor e aluno.
} 
relacionados aos pressupostos filosóficos e pedagógicos da formação técnica do curso em questão. Além disso, é importante destacar que os objetivos e o perfil de formação em nível médio, de Controle Ambiental, serão discutidos, descritos e interpretados de maneira crítica e reflexiva, a partir de referências que discutem a educação (DEMO, 2005; FREIRE, 2002; 2014a; 2014b; MÉSZÁROS, 2008; SERRES, 1993; VANZUITA, 2021).

Começamos, portanto, por abordar como os princípios filosóficos e pedagógicos do curso são mencionados no PPCTM (IFC, 2019a). A caracterização dos princípios filosóficos e pedagógicos do PPCTM (IFC, 2019a), estão fundamentados em documento institucional do IFC, denominado "Diretrizes para a Educação Profissional Integrada ao Ensino Médio" (IFC, 2019b), em que compreende o processo formativo a partir de uma

[...] formação humana que toma a perspectiva da integração de todas as dimensões da vida no processo educativo, visando a formação omnilateral, de modo a integrar, de forma unitária, as dimensões fundamentais da vida: o trabalho (como princípio educativo), o conhecimento (ciência e tecnologia) e a cultura, numa superação da dualidade entre Educação Básica e Educação Técnica (IFC, 2019a, p. 15-16).

Nesse contexto, a formação técnica em Controle Ambiental procura provocar, por meio da perspectiva da formação humana, sobretudo, a integração dos três aspectos relacionados a vida de cada um, ou seja, a articulação crítica e complexa entre o trabalho, o conhecimento e a cultura. A integração crítica, contextualizada e reflexiva dessas três dimensões no contexto de formação não é nova (FREIRE, 2002; 2014a; 2014b; VIEIRA PINTO, 2005), mas parece fundamental em qualquer projeto educativo e formativo ao mesmo tempo que almeja a formação de cidadãos/sujeitos críticos, autônomos e emancipados. Portanto, o curso, através do que apresentou no PPCTM (IFC, 2019a), pode oportunizar aos estudantes uma formação técnica, crítica, contextualizada e integrada do conhecimento, do trabalho e da sua cultura no contexto educativo e formativo.

O documento anuncia (IFC, 2019a, p. 18), a partir da formação integral, a perspectiva da abordagem sócio-histórica, fundamentada no materialismo dialético como pressuposto dos processos de formação dos estudantes. Pelo entendimento que se tem desse processo, não há uma hierarquização dos conhecimentos técnicos em detrimento dos conhecimentos sociais ou das humanidades, uma vez que as fronteiras do conhecimento não estão delimitadas, nem tampouco fragmentadas, ou seja, a proposta formativa é de abordagem interacionista e dialética. Nessa perspectiva, é citada uma 
disciplina descrita como Laboratórios de Práticas Orientadas (LPPO), em que tem como objetivo o desenvolvimento de possibilitar a integração de conhecimentos desenvolvidos no curso através de projetos que visem a resolução de problemas no âmbito do IFC Campus Camboriú ou da Bacia Hidrográfica de Camboriú e/ou região (IFC, 2019a, p. 19).

Nesse sentido, desenvolver uma prática formativa e educativa que priorize articular conhecimentos e provoque nos(nas) formandos(as) a possibilidade de investigação e de novos aprendizados, por meio de projetos, visando buscar repostas para os problemas locais, principalmente aqueles ligado a educação ambiental, é significativo, uma vez que oportuniza que os(as) formandos(as) possam exercitar a autoria, autonomia formativa e, principalmente, a construção do conhecimento inovador. É possível perceber a perspectiva do aprendizado formativo para a vida na disciplina de LPPO na formação técnica, quando a formanda E2 menciona o seu aprendizado nesse contexto: "Laboratório de Práticas Profissionais Orientadas foi, não sei se tanto na minha na minha formação acadêmica, mas a minha formação pessoal. O laboratório de gestão de resíduos é uma coisa que uso até hoje para separar o meu lixo em casa, para reciclar em casa, em qualquer lugar que eu vou, então, sem dúvida, esse laboratório foi o mais importante para mim".

O desenvolvimento do pensamento formativo para a vida é, portanto, significativo/com sentido quando os(as) formandos(as) conseguem relacionar o conhecimento aprendido no contexto da instituição e articulá-lo/utilizá-lo na sua própria experiência vivida. Trata-se de desafiar os(as) formandos(as) no caminho da investigação e da "[...] curiosidade epistemológica [...]", para “[...] que vá percebendo na e pela própria prática, sujeito capaz de saber" (FREIRE, 2002, p. 140). É nesse sentido que a formação numa perspectiva progressista, crítica e emancipatória procura provocar experiências por meio de projetos de pesquisa ou ações de investigação, como na disciplina de LPPO, exercitando a “[...] curiosidade epistemológica indispensável à produção do conhecimento" (FREIRE, 2002, p. 141). Os conhecimentos ligados ao campo da educação ambiental são destaques no curso técnico de Controle Ambiental e permitem que os estudantes consigam combinar e associar tão bem ou melhor os conhecimentos técnicos dessa área com a própria experiência de vida no contexto da família e na sociedade. 
Outro exercício importante para o desenvolvimento dos princípios filosóficos e pedagógicos no contexto da formação técnica em Controle Ambiental prevista no PPCTM (IFC, 2019a) é a metodologia de Projetos de Trabalho, em que preconiza nos processos de aprendizagem, a construção ativa dos conhecimentos sociais e culturais articulados aos conhecimentos das próprias experiências de vida discentes. Esses aspectos se fundam, principalmente, por meio de estratégias em que a pesquisa, como processo e método de aprendizado, possibilita aos(as) formandos(as) que estudem contextos diferenciados, articulem saberes, comparem realidades diversas, elaborem conhecimentos significativos e inovadores para a formação técnica em Controle Ambiental. Compreende-se que este é um movimento dialógico e dialético em razão de oportunizar o aprendizado em processo e em permanente reconstrução, avaliando e interpretando constantemente o conhecimento aprendido e (re)significado no contexto formativo, criando métodos e metodologias para aprender bem (VANZUITA, 2021).

A partir da discussão dos princípios filosóficos e pedagógicos, o objetivo geral de formação, contido no PPCTM é: "Formar técnicos de nível médio, aptos a praticar atividades de monitoramento, controle e gerenciamento ambiental visando a sustentabilidade" (IFC, 2019a, p. 21). Como desdobramentos do objetivo geral, os objetivos específicos são:

Identificar e avaliar os processos de degradação da natureza e os parâmetros de qualidade ambiental do solo, água e ar; Analisar, propor e aplicar metodologias de recuperação ou de restauração ambiental em ambientes degradados; Analisar as tecnologias de controle e tratamento de emissões de poluentes para o solo, água e ar; Analisar os aspectos sociais, econômicos, culturais e éticos envolvidos nas questões de exploração dos recursos naturais; Auxiliar na implementação de sistemas de gestão ambiental em organizações; Desenvolver atividades voltadas para o uso racional de água e energia, tratamentos simplificados de sistemas de águas e efluentes e de limpeza urbana; Conhecer e aplicar a legislação ambiental; Planejar e atuar em projetos de educação ambiental; Cumprir normas de segurança do trabalho; Atuar em equipe demonstrando capacidade para liderança, agindo com responsabilidade, ética e criatividade (IFC, 2019a, p. 2122).

Conforme os objetivos apresentados no PPCTM (IFC, 2019a), observa-se que as atividades relacionadas ao exercício profissional específico em técnico de Controle Ambiental, são direcionadas à ações que requerem alto grau de formação, com qualidade formal e política na perspectiva de Demo (2005), em razão de que os verbos de ação 
identificados na proposta formativa são complexos e exigem o pensamento crítico, autonomia formativa e competência humana histórica (DEMO, 2005) bem desenvolvidas como: praticar, identificar, avaliar, analisar, propor, aplicar, auxiliar, desenvolver, conhecer, cumprir e atuar. Nesse caso, a competência humana histórica é a "[...] condição de não apenas fazer, mas de saber fazer e sobretudo refazer permanentemente nossa relação com a sociedade e com a natureza, usando como instrumento crucial o conhecimento inovador" (DEMO, 2005, p. 13).

Portanto, no processo formativo do técnico em Controle Ambiental “[...] a atividade reconstrutiva não se esvai no reescrever, mas abrange, num todo só, o desafio de inovar, intervir, praticar” (DEMO, 2005, p. 29). A educação ou a formação, nesse caso, estimula ou provoca o que Serres (1993, p. 95) chama de “invenção” isto é, “[...] o único ato intelectual verdadeiro, a única acção de inteligência. O resto? Cópia, disfarce, reprodução, preguiça, convenção, batalha, sonho. Apenas ela suscita a descoberta. [...] Eu penso, logo invento, eu invento, logo penso [...]".

Por meio dessa discussão relacionada aos objetivos de formação, o perfil do egresso do curso técnico de Controle Ambiental do IFC Campus Camboriú deverá possuir: "[...] formação humanística e cultural integrada à formação técnica, tecnológica e científica. Pautado pelos princípios da democracia, da autonomia e da participação crítica e cidadã, o egresso está habilitado a compreender que a formação humana e cidadã precede a qualificação técnica para o mundo do trabalho" (IFC, 2019a, p. 29). É importante destacar que o perfil do egresso é situado no contexto democrático e cidadão em que estamos inseridos na atualidade do início do século 21.

Por conta disso, é pertinente afirmar que os processos formativos, por meio do PPCTM (IFC, 2019a), estão articulados a uma educação crítica, reflexiva e principalmente humana. Dessa maneira, identificamos a formação técnica em Controle Ambiental do IFC Campus Camboriú como uma educação "para além do capital" (MÉSZÁROS, 2008), uma vez que mobiliza-se contra a lógica neoliberal e dos valores dos interesses dominantes, causados pelas reformas educacionais contemporâneas (BRASIL, 2017), em razão de provocar uma educação humanista e centrada no conhecimento inovador e crítico-reflexivo. Portanto, o perfil do egresso do curso de Controle Ambiental está alinhado a abordagem dos princípios filosóficos e pedagógicos do curso, bem como está articulado aos objetivos de formação. 
Por meio da análise interpretativa e descritiva do PPCTM (IFC, 2019a) foi possível identificar que a formação técnica de nível médio em Controle Ambiental pode oportunizar nos processos formativos o exercício crítico e contextualizado do aprendizado, por meio de estratégias que provocam a autonomia formativa, elaboração do conhecimento, pensamento crítico e reflexivo. Nessa perspectiva, afirmamos que as experiências de formação inicial e inserção profissional contribuem com a construção de identidade(s) profissional(is) articuladas aos processos de pesquisa como princípio educativo e formativo e criação de métodos e metodologias para aprender bem (VANZUITA; HOEPERS; TAKAYAMA; FERNANDES, 2020; VANZUITA, 2021).

\section{PROCEDIMENTOS METODOLÓGICOS}

Pautada na abordagem qualitativa, no primeiro momento, foram investigados onze (11) formandos(as) do curso técnico integrado ao ensino médio em Controle Ambiental, mediante a aplicação do questionário semiestruturado, composto por (11) questões abertas e fechadas em plataforma on-line, enviadas diretamente ao (e-mail) dos(as) formandos(as). No segundo momento da pesquisa, foi realizada a coleta de dados por meio do uso da técnica de grupo focal (GATTI, 2012), orientado por um roteiro constituído de nove (9) perguntas, com a participação de cinco (5) formandos(as) que já haviam respondido o questionário.

Foi realizada a descrição e interpretação da empiria, uma vez que as análises foram articuladas aos aspectos teóricos e conceituais que fundamentam esta investigação. A triangulação dos dados ocorreu a partir das percepções dos(as) estudantes quanto à formação inicial, inserção profissional e os impactos desses aspectos na construção de identidade(s) profissional(is).

No processo de análise, após a tabulação dos dados e transcrição dos diálogos, os codinomes criados para os(as) formandos(as) participantes do questionário semiestruturado foram elaborados utilizando a letra F, para identificar os(as) formandos(as), seguida do número, constituído pela ordem das respostas recebidas: "F1; F2 etc”. No grupo focal, a identificação foi realizada por meio da letra E, o que significa estudante, seguida do número para diferenciar a participação dos sujeitos da pesquisa: "E1, E2 etc".

A análise-descritiva e interpretativa ocorreu após os processos de transcrição dos dados coletados. A partir desse movimento, foram elaboradas quatro (4) categorias de 
análise: a) escolha profissional: percepções dos(as) formandos(as) em Controle Ambiental; b) relação teoria e prática nos processos formativos; c) metodologias ativas e d) inserção profissional: o estágio no contexto formativo.

Portanto, exigiu-se dos(as) pesquisadores(as) uma acurada preocupação em descrever, analisar a luz dos autores e interpretar os dados de maneira que o leitor possa identificar o que pensam, como e por que os(as) formandos(as) compreendem a formação inicial e inserção profissional da forma que eles apresentaram nas discussões do questionário e grupo focal (TRIVIÑOS, 2011). A pesquisa foi avaliada pelo Comitê de Ética em Pesquisa com Seres Humanos (CEPSH) do IFC Campus Camboriú. Obteve o parecer aprovado na data de 17 de fevereiro de 2020, com o número 3.843.216.

\section{ESCOLHA PROFISSIONAL: PERCEPÇÕES DOS(AS) FORMANDOS(AS) EM CONTROLE AMBIENTAL}

As onze (11) respostas do questionário semiestruturado permitiram identificar o perfil estudantil dos sujeitos investigados. Dentre os respondentes, seis (6) são do sexo masculino e cinco (5) do sexo feminino, estudantes do terceiro ano do curso investigado.

Sobre os motivos que levaram a escolherem o curso técnico em Controle Ambiental, a partir das respostas do questionário semiestruturado, várias foram as razões para a escolha, codificadas em três grandes eixos: 1) identificação com o curso e afinidade com a área do meio ambiente; 2) orientação familiar e; 3) carga horária do curso. No que se refere aos processos de identificação com a área de conhecimento, estudos de Vanzuita (2018a; 2018b) demonstram que formandos(as) em Educação Física escolhem essa área de conhecimento por entenderem que identificam-se com o esporte e atividades físicas no contexto profissional. Correlacionando as pesquisas de Vanzuita (2018a; 2018b) com os dados da presente investigação, é possível identificar que os(as) formandos(as) do curso técnico de Controle Ambiental também mencionaram que escolheram o curso por identificarem-se com a área de atuação profissional e por entenderem que a problemática do meio ambiente é assunto contemporâneo e atual.

No que se refere ao eixo da orientação familiar, apenas um formando mencionou que escolheu o curso por considerar as "recomendações dos familiares" (F8). O estudo de Soares (2009, p. 69-77) indica que existem vários fatores para a escolha profissional, tais como: "[...] influências sociais, influências psicológicas e expectativas familiares". Os três fatores estão diretamente relacionados com as experiências que os(as) 
participantes tiveram a possibilidade de vivenciar no decorrer do processo de amadurecimento. A influência psicológica e a expectativa familiar, muitas vezes, direciona a escolha de jovens, mas, no entanto, como afirma Soares (2009, p. 74), "[...] Com tantas influências e dificuldades, como é possível alguém escolher?! [...]", diante de um contexto tão carregado de pressões, desejos e fantasias imaginadas por aqueles que são tão caros aos sujeitos(as) que escolhem ou pela influência da própria sociedade.

O eixo da carga horária do curso apresenta-se pouco expressivo no contexto da pesquisa, embora tenha sido apontado como uma dimensão de escolha dos(as) sujeitos(as) desta investigação. Sabe-se que o curso técnico em Controle Ambiental permite aos estudantes três tardes sem atividades de ensino, no IFC Campus Camboriú. Por conta dessa oportunidade, os estudantes sentem-se mais seguros e confortáveis em escolher o curso técnico em Controle Ambiental como possibilidade de formação profissional.

A dimensão de escolha pelo curso por conta das "matérias" ou conhecimentos que são tratados no Exame Nacional do Ensino Médio (ENEM), foi também mencionado pelo formando E1. Como os professores da área propedêutica do ensino médio integrado dos cursos técnicos do IFC Campus Camboriú têm formação em nível de mestrado e doutorado, é relevante mencionar que os processos formativos podem ser desenvolvidos através de orientações por meio da pesquisa como princípio educativo e formativo e criação de métodos e metodologias para aprender bem, em razão das experiências em desenvolver práticas de pesquisa e extensão no contexto institucional. Destacamos que por conta da formação stricto sensu dos professores do IFC Campus Camboriú é relevante afirmar que possivelmente aconteçam práticas que se revelam superadoras da transmissão de conhecimento nos processos formativos.

Diferente do que apareceu no instrumento do questionário semiestruturado, com relação aos processos de escolha pelo curso técnico em Controle Ambiental, no grupo focal ficou muito evidente outra situação: a escolha pelo curso sem motivos ou critérios definidos ou de forma pouco planejada. Foi identificado que três (3), dos(as) cinco (5) estudantes participantes do grupo focal mencionaram no seus processos de "escolha profissional" que motivaram-se em escolher o curso sem a perspectiva de realmente conhecerem as dimensões dos conhecimentos desenvolvidos no contexto formativo, como também sem um planejamento sistematizado para o ingresso nesse curso.

É importante destacar que as experiências no ensino fundamental, muitas vezes, não conseguem provocar nos estudantes um possível direcionamento no que se refere à 
possibilidade de uma escolha profissional mais assertiva, direcionada e bem planejada. $\mathrm{O}$ estudo de Silva (2017), aborda que os estudantes investigados no contexto formativo do curso técnico em Controle Ambiental, escolheram o curso sem planejamento prévio e com nenhum critério objetivo para a entrada nessa área de conhecimento. Levando em consideração essa situação de pesquisa, observamos nos relatos dos(as) formandos(as) do curso técnico em Controle Ambiental do IFC Campus Camboriú essa perspectiva:

Ah, eu não sei dizer exatamente o que me levou a escolher o curso de Controle Ambiental... foi aquilo, tem quatro cursos e eu tenho que escolher um em si. Eu fiquei entre Informática e Controle Ambiental [...] eu fiquei entre Controle Ambiental e Informática porque Informática sempre foi uma área que eu me interessei e o Controle Ambiental era uma coisa que... era como eu posso te dizer... era uma incógnita eu não sabia dizer o que era aquilo e eu fiquei muito interessado porque en fiquei curioso pra saber o que se tratava isso, sabe? (E3).

Controle Ambiental [...] por ser desconhecido eu tinha mais chance de gostar, por isso que eu escolhi esse curso, mas hoje eu vejo que realmente foi a melhor escolha ... basicamente isso (E4).

Bom eu escolhi o curso técnico de Controle Ambiental porque... Entre as quatro opções, eu acho que... Eu pensei que seria o que mais ia agregar na minha vida. Por que eu não sou da área da Agropecuária, não cresci nesse ramo, então... Não era minha primeira opção e também a Hospedagem eu acho que não ia me encaixar. Informática nem pensar, porque eu sou péssima com qualquer coisa, com internet ou tecnologia. E aí surgiu a oportunidade de fazer Controle, e eu ingressei no instituto (E2).

Assim como demonstrou Silva (2017), quanto nesta pesquisa, a escolha dos alunos pelo curso Técnico em Controle Ambiental não tem sido feita de forma planejada, em razão de que se trata, possivelmente, de uma escolha fundada em critérios relacionados a possibilidade de realização profissional com o curso ou com o futuro ingresso em um curso superior. Nesse sentido, é fundamental observar que os cursos do IFC Campus Camboriú necessitam desenvolver atividades de divulgação nas redes de ensino da região e estabelecer um maior contato com a sociedade externa, para oportunizar aos futuros ingressantes o conhecimento sobre cursos técnicos integrados ao ensino médio que oferece, em razão de possibilitar escolhas mais assertivas, evitando, dessa forma, a evasão e a desistência escolar dos estudantes interessados, mas pouco esclarecidos.

\section{A RELAÇÃO TEORIA E PRÁTICA NOS PROCESSOS FORMATIVOS}


Os relatos dos(as) formandos(as) possibilitam refletir sobre a importância pedagógica de relacionar os conhecimentos do contexto vivido com os processos de ensino e aprendizagem, sobretudo, no que diz respeito à relação que se estabelece entre teoria e prática e seus contributos para o processo formativo. Em se tratando da "prática" no processo formativo, estamos compreendendo esse movimento como uma ação reflexiva e contextualizada que necessita ser considerada no sentido do que Freire (2002) compreende, ao afirmar que, o ensinar e o aprender exigem compreensão da realidade e que, deve considerar a essencialidade de uma prática que conduza os estudantes a trilharem um caminho mais seguro no exercício das atividades a serem desenvolvidas. Em outras palavras, trata-se da reflexão crítica entre teoria e prática para que esta se torne emancipadora a tal ponto que ganhe sentido para a própria vida e na construção de identidade(s) profissional(is) dos(as) estudantes.

Nesta perspectiva, observemos a seguir, alguns excertos das narrativas dos alunos que, por sua vez, expressam os sentimentos e/ou impressões vivenciados por eles no processo de apreender e articular a relação teoria e prática: "[...] aquilo vai marcar para gente” (E3); “[...] essa experiência é muito boa pro nosso [...], não só pra seguir na área, não para faculdade, mas para vida” (E2); “[...] que juntas elas fazem bastante sentido" (E1), ou ainda, "[...] são pequenas coisas que contribuem para nossa formação" (E1). Tais relatos, parecem ir além da interseccionalidade oriundas do devir teórico-prático, pois imprime nas memórias dos estudantes uma práxis marcante que se afirma e confirma pelos detalhes da descrição, quando a formanda E5 recorda-se, por exemplo, da chaleira elétrica levada pelo professor: "[...] o professor sempre levava as coisas lá pra sala pra mostrar para a gente, sempre levava”.

No exercício que decorre do movimento da teoria à prática ou vice-versa, os alunos são levados a explorar sua criatividade e poderão, inclusive, se autoprojetar na inserção ao mundo do trabalho, aqui entendido como princípio educativo que se constitui na formação de si que se comunica com a formação do(s) outro(s). Vejamos: " [...] $a$ questão do estágio, ele te traz conhecimentos não só na área ambiental, ele traz. conhecimento assim, de como lidar com pessoas" (E2). No entanto, cabe considerar que tal práxis não ocorre de forma linear, pois para que a teoria se torne de fato uma prática educativa, formativa e emancipadora é preciso cultivar nos alunos por meio da troca de saberes, o sentido do porquê fazer o que se faz. 
Observemos quando o formando E3 relata: "[...] não é simplesmente uma decoreba, a gente tem que executar aquilo lá, então a gente tem que aprender". Encontramos aqui o desafio de problematizar a questão do aprender e de relacionar a teoria e a prática. Seria apenas o ato de "executar" os conteúdos teóricos aprendidos? Seria, por acaso, o ato de aprender a executar? Não parece a perspectiva do formando E3 apenas aprender por aprender ou aprender a executar uma técnica desenvolvida no contexto do curso. Aproxima-se mais da concepção de Demo (2008, p. 22), sobre o conceito de aprendizagem discutido por E3: “[...] aprendizagem se expressa na arte de argumentar e contra-argumentar com base na autoridade do argumento; [...] aprendizagem aparece na habilidade de fundamentar o que se diz, mantendo a percepção de que nada se diz em última instância peremptória”.

Nessa direção, podemos observar ainda, por exemplo, o que nos aponta o formando E1 ao afirmar: "[...] não chega a ser uma trilha só, para fazer trilha, mas uma trilha que a gente fez, a gente meio que desbravou o campus, entendeu?!’. Pelo contexto da narração é possível deduzir que "desbravar" denota um sentido de protagonismo em que o aluno compreende que sua ação e seu papel no ato de aprender não se reduz ao de mero espectador, antes, porém, o aluno se vê como participante ativo no processo de aprendizagem que é, ao mesmo tempo, singular e coletivo. Sob essa perspectiva Freire (2002) nos conduz a refletir

Quando vivemos a autenticidade exigida pela prática de ensinaraprender participamos de uma experiência total, diretiva, política, ideológica, gnosiológica, pedagógica, estética e ética, em que a boniteza deve achar-se de mãos dadas com a decência e seriedade [...]. O que quero dizer é o seguinte: quanto mais criticamente se exerça a capacidade de aprender tanto mais se constrói e desenvolve o que venho chamando "curiosidade epistemológica", sem a qual não alcançamos o conhecimento cabal do objeto (FREIRE, 2002, p, 26-27).

Corroborando com tal afirmação, Vanzuita; Raitz; Garanhani (2020) apontam que a confluência entre teoria e prática deve dar-se num contexto pedagógico e formativo que levem os estudantes ao conhecimento de novas referências e a reflexão de outros saberes, como por exemplo, no caso do estágio: "Quando os(as) formandos têm a oportunidade de se inserir em espaços formativos que possibilitam a articulação entre a teoria e prática profissional, é um momento de lançar mão dos conhecimentos e habilidades teóricometodológicas recebidas" (VANZUITA; RAITZ; GARANHANI, 2020, p. 70). 
Em outras palavras, compreendemos que o exercício de uma prática crítica e reflexiva no processo recíproco de troca e aquisição de conhecimentos, possibilita que as ações pedagógicas tornem-se repletas de sentidos para os(as) formandos(as), a tal ponto de que esses, se apropriam em suas memórias detalhes tão minuciosos das experiências vivenciadas no momento de associar teoria e prática: "Lembro da professora $X X X$ levando um pacote de algas assim para a gente comer, que ela estava falando sobre algas e tal. São pequenas coisas que contribuem para nossa formação entendeu?! Contribuiu para nosso aprendizado que depois tu acabas lembrando" (E1). É nessa relação entre teoria e prática que a formação inicial e inserção profissional contribui para construir identidade(s) profissional(is) mestiças articuladas aos processos de pesquisa como princípio educativo e formativo e criação de métodos e metodologias para aprender bem (VANZUITA, 2018a; 2018b; 2021).

\section{METODOLOGIAS ATIVAS}

Esse contexto pedagógico e formativo que leva o estudante a uma articulação entre teoria e prática, perpassa também pelas metodologias utilizadas no processo educativo. As metodologias ativas tratam-se das estratégias de ensino em que os(as) estudantes saem da passividade, no qual apenas os aspectos como ouvir e copiar não são considerados pertinentes, contudo, os(as) estudantes passam a ser protagonistas do seu processo de aprendizagem. O professor é orientador atento, problematizador, e o estudante, se encontra como protagonista e autônomo durante esse processo, que visa a construção do conhecimento e não somente a sua transmissão. Nessa perspectiva, teóricos como Demo (2005; 2008; 2011; 2015), Freire (2002), Dewey (1976) discorrem sobre o papel da educação como processo que leve de autonomia, autoria e produção de conhecimento nos estudantes, no sentido de superar as tendências apenas voltadas a passividade enfadonha dos(as) estudantes no contexto formativo.

Em um contexto de aprendizagem que se utiliza de estratégias que levem a autoria e elaboração de conhecimento, os(as) estudantes podem desenvolver as articulações/conexões dos conteúdos, de forma que se apropriem desses conhecimentos, ampliando, reconstruindo e reinventando processos e/ou técnicas aprendidos no processo educativo. Essa questão foi abordada pelos formandos que relembraram das práticas mais marcantes durante a formação e, entre elas, apareceram os seminários nos quais os(as) 
formandos(as) estudam e buscam o conhecimento para apresentar para sua turma. Outras situações interessantes sobre as práticas de aprendizagens ativas, foram as denominadas como "jogo de Biologia" e "Teatro História", pelos quais possibilitaram a aprendizagem significativa dos(as) formandos(as).

Contribuiu bastante assim, foi a questão de seminários, o aluno busca conhecimento. Não só o professor passa conteúdo e o aluno faz uma prova, mas sim que o aluno busca conhecimento e o professor orienta, eu acho que esse é o método que devia ser mais aplicado. Devia ser o principal método aplicado, não só uma exceção (E4).

Um jogo de Biologia que a gente fez, era jogo de Biologia se eu não me engano, era sobre angiospermas e gimnospermas. Foi bastante legal, assim, contribuiu bastante em relação a isso. Tinha que estudar, tinha uma competitividade (E1).

Também a matéria de XXX que a gente teve com professor XXX no primeiro e na metade do segundo ano que ele aplicava o método do Teatro História, assim o fato dele só dar essa oportunidade para os alunos expressarem e passar o conteúdo e colocar na prática, assim, exemplificar e vivenciar é muito importante. Claro que às vezes na prática não sai como a gente gostaria, às vezes o aprendizado não é da forma que a gente gostaria, mas, a intenção do projeto é maravilhosa, você sair desse método tradicional do professor explicando e aluno só recebendo e você dá oportunidade para aluno explorar a criatividade, explorar sua potencialidade. Nossa, isso é a intenção. É muito boa e eu sei que tem muitas... muitas coisas assim para melhorar, mas essa experiência eu acho que é muito válida, a tentativa do professor de juntar o conhecimento com a prática é uma coisa muito valiosa (E2).

O desenvolvimento de atividades que provoquem os(as) estudantes a estudar e buscar novos conhecimentos é fundamental no contexto formativo e educacional. Somente em ambiente de aprendizado que solicite a autonomia e autoria dos(as) sujeitos(as) em formação possibilitará construir cidadãos críticos, reflexivos e emancipados nos processos formativos e de inserção profissional (ANDRADE; FIGUEIREDO, 2021). Nesse sentido, o(a) professor(a) necessita cuidar para que os(as) estudantes "aprendam bem", solicitando deles o domínio da leitura, contraleitura, do estudo sistemático de textos e contextos, da elaboração própria, do saber pesquisar, questionar e autoquestionar criticamente a sociedade do qual faz parte, contribuindo, dessa maneira, para qualificar socialmente a construção de identidade(s) profissional(is) (DEMO, 2011; VANZUITA, 2018a; 2018b; 2021).

Em pesquisa realizada no contexto de Portugal, Alves (2006, p. 57) ao entrevistar jovens estudantes, relata que "[...] a maioria dos alunos considera que aprende melhor 
quando os professores explicitam o sentido das aprendizagens e quando utilizam estratégias que implicam o envolvimento dos sujeitos aprendentes na produção de conhecimento". Observamos, a partir das percepções dos(as) formandos(as) que essa perspectiva formativa também é desenvolvida no âmbito do IFC Campus Camboriú, no curso de Controle Ambiental. Portanto, é possível inferir que a construção de identidade(s) profissional(is) de formandos(as) do curso técnico em Controle Ambiental passa também pela articulação da pesquisa como princípio educativo e formativo e criação de métodos e metodologias nos processos de formação inicial.

\section{A INSERÇÃo PROFISSIONAL: O ESTÁGIO NO CONTEXTO FORMATIVO}

Durante a pesquisa realizada, os estudantes descreveram a importância do estágio para a inserção profissional, citando-o como um espaço em que podem relacionar o que foi aprendido na teoria, bem como desenvolver habilidades que somente são adquiridas durante esses momentos, como relatado pelos(as) formandos(as) E2 e E3:

Eu creio que contribuição é você conseguir ligar a teoria com a prática, você aprender na escola e você poder colocar isso em prática no estágio e nos projetos ambientais e nos laboratórios e todas as experiências que a gente teve (E2).

A gente teve essa experiência do que a trabalhar realmente, é além da questão como eu tinha falado do aprendizado, um pouco, às vezes, até além do que a gente aprende na escola e como até acho que a E5 e a E2 falaram, de conectar o que a gente aprende na escola com que a gente pode aprender nossa vida profissional, sabe?! (E3).

A experiência do estágio durante o processo de formação possibilita o contato com realidade profissional de forma que favorece o conhecimento de novas realidades e oportunidades dentro ou fora do campo profissional em que atua. Bardagi et al (2006, p. 70) ao se fundamentar em outros autores, expõem sobre a importância do estágio como “[...] como exercício do papel profissional e fortalecimento da relação com a carreira, além de facilitar o estabelecimento de metas profissionais realistas". A formada E5, discorre sobre a importância do estágio relatando criticamente sua experiência no seu relato:

[...] eu acho que isso é uma questão muito importante para a gente ver a realidade e pensar no que a gente pode mudar, ou ver no que a gente pode trabalhar, nas outras áreas, sabe..!? Não só no conteúdo, mas ver que nem a gente já falou, na prática e ver com os nossos próprios olhos, 
assim, qual é a realidade do mundo lá fora, eu acho que me contribuiu muito, muito, muito, meu estágio (E5).

O depoimento da formanda E5 também corrobora com a perspectiva de Pimenta (2012, p. 168) sobre o estágio “[...] como uma atividade que traz os elementos da prática para serem objeto de reflexão, de discussão, e que propicia um conhecimento da realidade na qual irão atuar". A contribuição do estágio não se faz presente somente no campo técnico, da escolha da profissão, mas também de incluir jovens que ainda não tiveram nenhuma experiência profissional no campo de trabalho. O estágio do curso técnico em Controle Ambiental traz esses dois vieses, o da inserção profissional na área de atuação do curso, mas também como experiência de trabalho e de vida para os estudantes que nunca tiveram essas vivências, como relatado pela formanda $\mathrm{E} 2$ :

O estágio, ele te traz conhecimentos não só na área ambiental, ele traz. conhecimento de como lidar com pessoas. Foi meu primeiro estágio, nunca tinha trabalhado, então, essa experiência de estar no escritório, estar com pessoas sérias. Então, essa experiência é muito boa pro nosso... não só pra seguir na área, não para faculdade, mas para vida (E2).

Estar no ambiente profissional, durante o estágio fortalece a autonomia dos estudantes contribuindo para a construção da sua(s) identidade(s) profissional(is) e gerando confiança para que esse jovem imerso no mundo de trabalho esteja seguro de sua escolha, seja na área de atuação do curso técnico escolhido ou em outras áreas. Nesse sentido, a possibilidade de ingressar no campo do trabalho desde a formação inicial causa experiências qualificadoras, aproximando os saberes teóricos e práticos da profissão, diminuindo, dessa forma, as preocupações e incertezas na transição da educação técnica de nível médio ao mundo do trabalho ou ao ingresso no ensino superior.

A respeito dos processos de inserção profissional, os(as) formandos(as) indicam que as experiências de estágio oportunizam colocar em prática os conhecimentos apropriados no contexto do IFC. Notamos essas dimensões nos depoimentos dos(as) formandos(as) a seguir:

Vivenciar um ambiente de trabalho em uma Fundação Municipal, conhecendo de perto os processos de licenciamento ambiental. Saber interpretar e aplicar os conceitos teóricos nas situações da realidade (F7).

Aprendi a pesquisar muito para fazer qualquer tipo de trabalho ou prova, coisa que não fazia antes porque não achava necessário (F1). 
Por meio do meu estágio, conheci quatro (4) cooperativas de reciclagem (em Passo Fundo - RS) e trabalhei com tabelas mensais destas (de 2015 até 2019), contendo: Quantidade (peso) arrecadado de cada produto pelas cooperativas; valor pago pelos compradores; salário dos cooperados; entre outras informações que ressaltaram a importância da reciclagem e de uma boa gestão das cidades em relação a coleta de lixo e educação ambiental (F4).

Algo que vi como o curso agregou na minha vida foi fazer estágio na FUCAM, onde os conceitos e as Leis que utilizamos em Legislação Ambiental são utilizados para a Fiscalização Ambiental! (F5).

O estágio em si foi uma grande experiência profissional e pessoal, por colocar em prática muito do que nos foi ensinado me ajudando a entender melhor e a relembrar (F11).

No estágio, pude colocar em prática diversas disciplinas técnicas que aprendi ao longo do curso, o que foi extremamente importante para o meu aprendizado (pude ver como as coisas funcionam de verdade, fora da sala de aula). Além disso, pude acompanhar os profissionais da empresa em seus trabalhos e projetos, o que me trouxe conhecimentos extras que posso aplicar no meu curso (F2).

A inserção profissional, por meio dos estágios, ajudam os(as) formandos(as) a compreender, na prática, os conhecimentos desenvolvidos ao longo da formação técnica em nível médio. Não poderia ser diferente, em razão de que a "[...] intencionalidade, a natureza social, a necessidade de ação conjunta e o trabalho humano [...]", são dimensões que contribuem com a apropriação de novos conhecimentos, assim como a oportunidade de revisão e avaliação dos conceitos teórico-práticos na prática profissional e educativa (PIMENTA, 2012, p. 109). Portanto, a inserção profissional, é compreendida como um processo individual, coletivo, histórico e socialmente inscrito no contexto em que acontece esse fenômeno (ROCHA-DE-OLIVEIRA, 2012).

É importante salientar que o estágio, entendido como processo de inserção profissional, coloca os(as) formandos(as) em contato direto e precoce com o contexto do trabalho, contribuindo com o aprendizado da profissão e colaborando para a elaboração do pensamento complexo e do conhecimento reconstrutivo e inovador (DEMO, 2005; MORIN; CIURANA; MOTA, 2003; MORIN, 2007). Com efeito, analisamos que a construção de identidade(s) profissional(is) dos(as) formandos(as) em Controle Ambiental, por meio de experiências de formação inicial e inserção profissional estão articuladas aos processos de pesquisa como princípio educativo e formativo e criação de métodos e metodologias no contexto do IFC Campus Camboriú. 


\section{CONSIDERAÇÕES FINAIS}

No processo de construção de conhecimento da presente pesquisa, delimitamos a questão-problema: como as experiências no contexto de formação inicial e inserção profissional de formandos(as) do curso técnico integrado ao ensino médio de Controle Ambiental do IFC Campus Camboriú impactam a construção de identidade(s) profissional(is)? Por meio desse questionamento, seguimos no caminho da investigação através da abordagem qualitativa, de característica analítico-descritiva e interpretativa a partir da coleta de dados recorrendo ao questionário semiestruturado e grupo focal, analisando as percepções dos(as) onze (11) formandos(as) em Controle Ambiental do IFC Campus Camboriú.

As experiências de formação inicial e inserção profissional do(as) formandos(as) em Controle Ambiental, desde as escolha pelo curso, até o processo de inserção profissional através do estágio, são desenvolvidas de maneira crítica e contextualizada, considerando a articulação entre teoria e prática, o uso de estratégias ativas de aprendizagem, assim como no estágio curricular em que os(as) formandos(as) puderam experimentar e vivenciar esses aprendizados recebidos no contexto formativo, comparando e avaliando esses conhecimentos no contexto da prática profissional. A escolha profissional pelo curso, não foi planejada para grande parte dos(as) formandos(as), no entanto, foi possível identificar que o curso trouxe grande identificação com a área de Controle Ambiental e contribuiu para que eles pudessem utilizar os conhecimentos nos momentos da prática profissional e na própria vida. Considerando que os estudantes investigados, na maior parte, não planejaram sua escolha pelo curso a partir da identificação com essa área de conhecimento, sugerimos que o IFC possa intensificar um maior contato com as redes de ensino e maior divulgação dos cursos ofertados no âmbito do Campus Camboriú, para oportunizar maior visibilidade e esclarecimento do que se propõe a oferecer no contexto da formação técnica em nível médio.

Com maior intensidade nos depoimentos dos(as) formandos(as) do curso técnico em Controle Ambiental, principalmente nos processos de formação inicial, apareceu a relação evidente e importante entre teoria e prática. Vários depoimentos relacionaram a aprendizagem significativa quando os professores procuram possibilitar práticas que os(as) façam construir relações entre os campos da prática educativa e profissional articulados aos conhecimentos desenvolvidos nas suas aulas. É importante destacar que 
ao solicitar dos(as) estudantes a pesquisa, a busca e o estudo, os estudantes sentiram-se mais motivados em aprender e ressignificar os conhecimentos tratados nos processos formativos. Como afirma Freire (2002, p. 52), quando menciona que “[...] ensinar não é transferir conhecimento [...]”, pressupõe que tanto os professores quanto os(as) estudantes precisam incorporar e apreender a criar possibilidades de elaboração própria e/ou construção de conhecimento inovador (DEMO, 2005), como foi identificado na presente pesquisa.

A partir dessas abordagens formativas, as estratégias ativas de aprendizagem desenvolvidas pelos professores foram identificadas nos depoimentos dos(as) formandos(as) no contexto das produção de dados. Mencionaram que estratégias como “jogo de Biologia" e "Teatro História” contribuíram para que estudassem e buscassem o conhecimento e as aprendizagens no que se refere à formação técnica em Controle Ambiental. Quando a perspectiva de formação oportuniza aos estudantes que busquem o conhecimento e possam reconstruí-los, a formação inicial atinge seu objetivo, ou seja, provoca aquilo que o próprio PPCTM (IFC, 2019a) dispõe como dimensão da formação, o desenvolvimento do pensamento crítico e reflexivo através das dimensões integradas relacionadas ao trabalho, o conhecimento e a cultura, permitindo a articulação qualificada entre a educação básica e a educação profissional técnica de nível médio. O curso em Controle Ambiental, portanto, tem possibilitado que os(as) formandos(as) exercitem a autoria, autonomia e o pensamento crítico e complexo ao mesmo tempo (MORIN, 2015; SERRES, 1993).

No que se refere à inserção profissional através do estágio, dimensão importante e fundamental nos processos de articulação entre teoria e prática na formação inicial dos(as) formandos(as), foi possível identificar que essas atividades contribuíram sobremaneira para que conseguissem observar e vivenciar a prática profissional de forma reflexiva e crítica simultaneamente. Assim, conhecer o contexto do trabalho em diferentes realidades e possibilidades de atuação profissional, aprender a fazer pesquisa, registrar e identificar os procedimentos relacionados ao trabalho técnico em Controle Ambiental, vivenciar experiências de trabalho relacionadas a área de conhecimento, colocar em prática os conhecimentos do curso na prática profissional, são alguns exemplos do que os processos de inserção profissional, por meio do estágio, proporcionaram aos(as) formandos(as) do curso técnico em Controle Ambiental do IFC Campus Camboriú. Através dos depoimentos críticos e reflexivos dos(as) formandos(as) do curso técnico em 
Controle Ambiental, foi possível identificar que as experiências de formação inicial e inserção profissional possibilitam construir identidade(s) profissional(is) articuladas pela pesquisa como princípio educativo e formativo e a criação de métodos e metodologias para aprender bem.

\section{REFERÊNCIAS}

ALVES, M. N. de C. Socialização escolar e profissional dos jovens: projetos, estratégias e representações. Portugal, Lisboa: Educa, Impressa de Coimbra Ltda, 2006.

ANDRADE, D. F. de; FIGUEIREDO, T. F. Metodologias ativas e participativas em uma disciplina de Educação Ambiental no ensino superior. Revista Brasileira de Educação Ambiental (RevBEA), v. 16, n. 2, p. 123-142, 2021. DOI: 10.34024/revbea.2021.v16.11205. Disponível em: https://periodicos.unifesp.br/index.php/revbea/article/view/11205. Acesso em: 25 out. 2021.

BARDAGI, M. et al. Escolha profissional e inserção no mercado de trabalho: percepções de estudantes formandos. Psicologia Escolar e Educacional [online], v. 10, n. 1, p. 69-82, 2006. Disponível em: https://doi.org/10.1590/S1413-85572006000100007. Acesso em: 15 ago. 2021.

BRASIL. Base Nacional Comum Curricular (BNCC). Brasília, MEC/CONSED/UNDIME, 2017. Disponível em: http://basenacionalcomum.mec.gov.br/images/BNCC_EI_EF_110518_versaofinal_site.pdf. Acesso em: 24 out. 2021.

DEMO, P. Educar pela pesquisa. 7. ed. São Paulo: Autores Associados, 2005.

DEMO, P. Metodologia para quem quer aprender. São Paulo: Atlas, 2008.

DEMO, P. Outro professor: alunos podem aprender bem com professores que aprendem bem. Jundiaí: Paco Editorial, 2011.

DEMO, P. Educar pela pesquisa. 10. ed. Campinas: Autores associados, 2015.

DEWEY, J. Experiência e educação. Tradução de Anísio Teixeira. 2. ed. São Paulo: Editora Nacional, 1976.

FREIRE, P. Pedagogia da autonomia: saberes necessários à prática educativa. 23. ed. São Paulo: Paz e Terra, 2002.

FREIRE, P. Educação como prática da liberdade. 38. ed. São Paulo: Paz e Terra, 2014a. Disponível em: https://cpers.com.br/wp-content/uploads/2019/09/5.-

Educa\%C3\%A7\%C3\%A3o-como-Pr\%C3\%A1tica-da-Liberdade.pdf. Acesso em: 17 set. 2020.

FREIRE, P. Pedagogia do oprimido. 54. ed. Rio de Janeiro: Paz e Terra. 2014 b.

GATTI, B. A. Grupo focal na pesquisa em ciências sociais e humanas. Brasília: Liber Livro Editora, 2012. 
IFC. INSTITUTO FEDERAL CATARINENSE. Projeto pedagógico de curso de educação profissional técnica de nível médio (PPCTM). Curso técnico de Controle Ambiental integrado ao ensino médio. Instituto Federal Catarinense, 2019a. Disponível em: http://www.camboriu.ifc.edu.br/wp-content/uploads/2014/06/PPC-2020-ControleAmbiental.pdf. Acesso em: 15 dez. 2021.

IFC. INSTITUTO FEDERAL CATARINENSE. Resolução no 16. CONSUPER/2019. Dispõe sobre as Diretrizes para a Educação Profissional Técnica Integrada ao Ensino Médio do Instituto Federal Catarinense. Instituto Federal Catarinense, 2019b. Disponível em: https://ifc.edu.br/wpcontent/uploads/2017/09/Resolu\%C3\%A7\%C3\%A3o-16.2019-Diretrizes-ANEXO.pdf. Acesso em: 15 dez. 2021.

MÉSZÁROS, I. Educação para além do capital. 2. ed. Tradução: Isa Tavares. São Paulo: Boitempo, 2008.

MORIN, E; CIURANA, E. R; MOTA, R. Educar na era planetária: o pensamento complexo como método de aprendizagem no erro e na incerteza humana. São Paulo: Cortez, 2003.

MORIN, E. Os sete saberes necessários à educação do futuro. 12. ed. São Paulo: Cortez; Brasília: UNESCO, 2007.

MORIN, E. Ensinar a viver: manifesto para mudar a educação. Porto Alegre: Silina, 2015.

PIMENTA, S. G. O estágio na formação de professores: unidade teoria e prática? 11. ed. São Paulo: Cortez, 2012.

VIEIRA PINTO, Á. O conceito de tecnologia. v. 1. Rio de Janeiro: Contraponto, 2005.

POUND, E. ABC da literatura. São Paulo: Cultriz, 2002.

ROCHA-DE-OLIVEIRA, S. Inserção profissional: perspectivas teóricas e agenda de pesquisa. Revista Pensamento Contemporâneo em Administração, Rio de Janeiro, v. 6, n. 1, p. 124135, jan./mar. 2012. Disponível em: < http://www.spell.org.br/documentos/ver/30875/insercaoprofissional--perspectivas-teoricas-e-agenda-de-pesquisa/i/pt-br>. Acesso em: 24 jul. 2021.

SERRES, M. O terceiro instruído. Portugal: Instituto Piaget, 1993.

SILVA, K. F. da. Saberes ambientais e projetos de vida de alunos concluintes de um curso técnico ambiental na rede federal de educação profissional, científica e tecnológica. 91f. Dissertação. (Mestrado em Educação Tecnológica). Centro Federal de Educação Tecnológica de Minas Gerais, Belo Horizonte, 2017.

SOARES, D. H. P. O que é escolha profissional. 4. ed. rev. e atual. São Paulo: Brasiliense, 2009.

TRIVIÑOS, A. N. S. Introdução à pesquisa em ciências sociais: a pesquisa qualitativa em educação. 1. ed. 20. reimpr. São Paulo: Atlas, 2011.

VANZUITA, A. A construção de identidade(s) profissional(is) de formandos em educação física da UFPR. 2018. 161f. Relatório de Pós-Doutorado. (Pós-Doutorado em Educação). Curitiba, UFPR, 2018a.

VANZUITA, A. A construção de identidade(s) profissional(is) em educação física. 1. ed. Curitiba: Editora Appris, 2018b. 
VANZUITA, A.; HOEPERS, I. da S.; TAKAYAMA, F. S.; FERNANDES, Flávia de Souza. A construção de identidade(s) profissional(is) de formandas em Pedagogia. The Fiep Bulletin, v. 90, p. 108-112, 2020. Disponível em:

http://www.fiepbulletin.net/index.php/fiepbulletin/article/view/6249. Acesso em: 15 dez. 2021.

VANZUITA, A.; RAITZ, T. R.; GARANHANI, M. C. Experiências de inserção profissional na construção de identidades profissionais de formandos em Educação Física. Boletim Técnico Do Senac, v. 46, p. 57-81, 2020. Disponível em: https://doi.org/10.26849/bts.v46i1.768. Acesso em: 15 dez. 2021.

VANZUITA, A.; GARANHANI, M. C. A formação inicial na construção de identidade(s) profissional(is) em educação física. Educação e Filosofia, v. 33, n. 69, p. 1583-1622, 10 jan. 2021. Disponível em: http://www.seer.ufu.br/index.php/EducacaoFilosofia/article/view/49146. Acesso em: 07 ago. 2021.

VANZUITA, A. Os impactos da escolha, formação inicial e inserção profissional na construção de identidade(s) profissional(is) em educação física. Curitiba: CRV, 2021.

\section{AGRADECIMENTOS}

Ao Conselho Nacional de Desenvolvimento Científico e Tecnológico (CNPq), pelo apoio financeiro à pesquisa; ao Instituto Federal de Educação Ciência e Tecnologia Catarinense (IFC), por oportunizar os meios para o desenvolvimento deste trabalho.

Recebido em: 03/01/2022

Aprovado em: 30/01/2022

Publicado em: 01/02/2022 